\title{
Blue ocean strategy application in the course of planning and implementation of construction projects in the area of SMART housing and social infrastructure
}

\author{
Alexandr K. Orlov ${ }^{1, *}$, Irina Y. Chubarkina ${ }^{1}$ \\ ${ }^{1}$ Moscow State University of Civil Engineering, Yaroslavskoye Shosse, 26, Moscow, 129337, Russia
}

\begin{abstract}
This paper deals with approaches to the analysis of competitiveness in the construction field. The methodology of blue ocean strategy was analyzed. Based on the conducted analysis a set of measures related to blue ocean strategy application in the course of planning and implementation of construction projects in the area of SMART housing and social infrastructure was developed. Implementation of the proposed methodological provisions will allow improving investment efficiency in the course of construction projects implementation and enhancing the competitive ability of the developer.
\end{abstract}

\section{Introduction}

The purpose of this paper is to develop a set of measures related to the efficient management of the developer's competitiveness in the course of planning and implementation of construction projects in the area of social infrastructure and SMART housing. Currently, different approaches towards the efficient management of competitiveness - conventional and unconventional - are widely used. As an example of a conventional approach one can consider the strategy proposed by American scientist Michael Porter [1]. According to this strategy (called the five forces model), the competitive analysis of construction industry allows to determine the competitive intensity in the course of planning and implementation of construction projects and select the position that allows to protect the developer against the influence of its competitors to the fullest extent as well as provide the developer with a possibility to exert influence on them.

The golden rule of Porter's five forces model is as follows: the lower the influence of competitive forces is, the more opportunities to get high profit the company has. And vice versa, the higher the influence of competitive forces is, the higher is the probability that no companies will be able to ensure high return from investments. However, the average profitability of the industry is the most powerful competitive force [1,2].

The strategy in this paper is considered using real estate market as an example taking into account social infrastructure. Social infrastructure facilities available in a housing

\footnotetext{
${ }^{*}$ Corresponding author: alor333@gmail.com
} 
complex or a development area have an impact, first, on increased demand and, second, on prices into which the developer includes the cost of an apartment at the initial stage.

So, the matter point of the problem related to management of the company's competitive ability in the area of social infrastructure is an increase in its adaptability, competitive advantages, operating profit and, consequently, an increase in the company's sustainability, flexibility and ability to survive $[3,4,5]$.

As stated above, a competitive struggle consists of the following two components: the construction industry including multiple competitors (conventional strategy) and an uncontested market space. The latter within the framework of this paper will be presented using the strategy called the blue ocean strategy. The key difference of this strategy is no drive to beat competitors. The theoretical basis of this research is presented by scientific provisions contained in works of scholars who study problems associated with the creation of a market niche distinguished by no competition [6-10].

However, competitiveness is the key indicator of the other (opposite) type of the abovementioned strategy called the red ocean. The higher the share of competitors on the market is, the lower potential profit market players receive and the higher an increase in expenditures for the sale of goods and services is. The blue ocean represents an unoccupied and unknown niche in the market that is formed in a new uncontested market area. It allows to occupy uncontested market areas, which can lead to an unbounded expansion of the industry and high profit gained by an enterprise over the long term.

By comparing the strategies of the red and blue oceans (Table 1), one can come to a conclusion that red ocean strategy represents infinite rivalry between market players for the most profitable conditions for production, sale and purchase of goods.

Table 1. Red and blue ocean strategies

\begin{tabular}{|c|c|}
\hline Red ocean strategy & Blue ocean strategy \\
\hline Compete in existing market space & Create uncontested market space \\
\hline Beat the competition & Make the competition irrelevant \\
\hline Exploit existing demand & Create and capture new demand \\
\hline Make the value-cost trade-off & Break the value-cost trade-off \\
\hline $\begin{array}{c}\text { Align the whole system of a company's } \\
\text { activities with its strategic choice of } \\
\text { differentiation or low cost. }\end{array}$ & $\begin{array}{c}\text { Align the whole system of a company's } \\
\text { activities in pursuit of differentiation and } \\
\text { low cost }\end{array}$ \\
\hline
\end{tabular}

Creation of a market inside a market can be distinguished as one of the methods of this strategy. A new market niche allows to be protected from competitors and form the pricing policy that will not be determined by competitive considerations.

\section{Methodology}

The methodological framework of this research is represented by generally accepted scientific methods and techniques ensuring comprehensive, logical and valid research results, including methods of scientific analysis and synthesis, grouping, comparison and generalization, and literature review. Qualitative analysis, economic analysis, financial simulation of cash flows and blue ocean strategy methodological approaches were also used in this paper.

As already mentioned, blue ocean strategy presupposes no drive to beat the competition. Value innovation is created instead of it. If compared to simple innovations that are usually accompanied by high costs and no guarantee that end users will like them for sure, the phrase "value innovation" points out the necessity to synthesize novelty, practicality and low costs. 
Value innovation is based on an equal focus on both value and innovation. Value without innovation usually results in onward and upward value creation, and that allows lifting value but not distinguishing it among competitors. In this regard, value innovation is something more than innovation [11]. It is the strategy that covers the entire system of the company's activities (Figure 1).

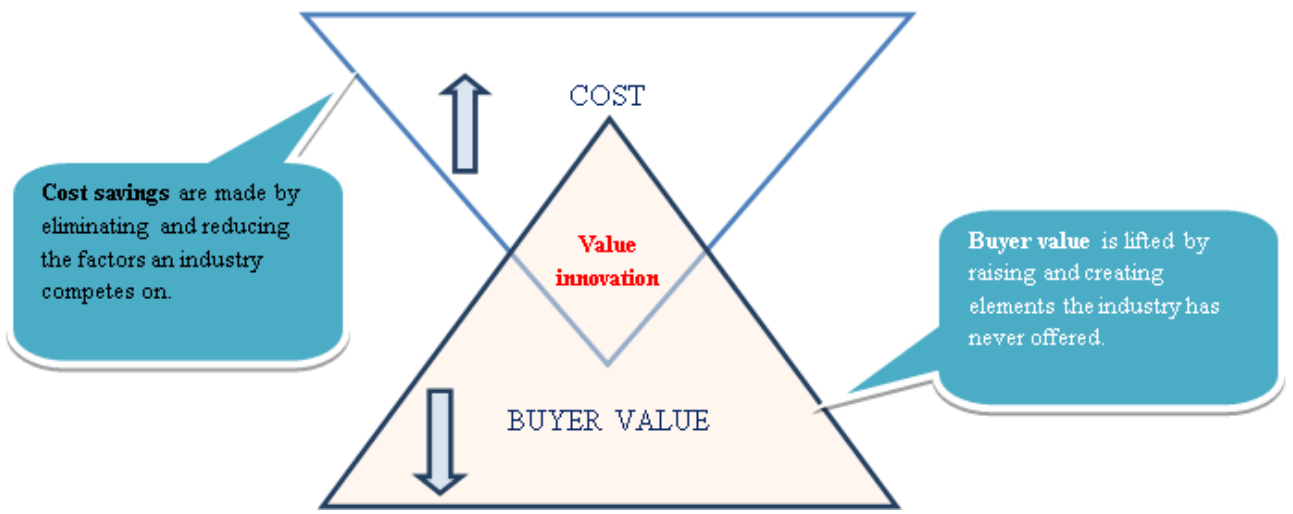

Fig.1. Value innovation

The main tool of this strategy is the strategy canvas that allows to carry out diagnostics and simulate future strategies (Figure 2). It serves as a reflection of the current situation on the market allowing to determine in what competing companies invest their funds, characteristics of products which are subject to competition, as well as to find out exactly what competitive offers customers receive on the market $[12,13]$. The main component of the strategy canvas is the value curve - a graphic representation by comparing the company's performance considering competitive factors.

When building the strategy canvas, companies should identify the basic characteristics of their own products and products by their competitors that are the subject of competition in the construction industry [14-16]. The Y-axis shows evaluations of competitive factors for every company or product. The $\mathrm{X}$-axis shows competitive factors.

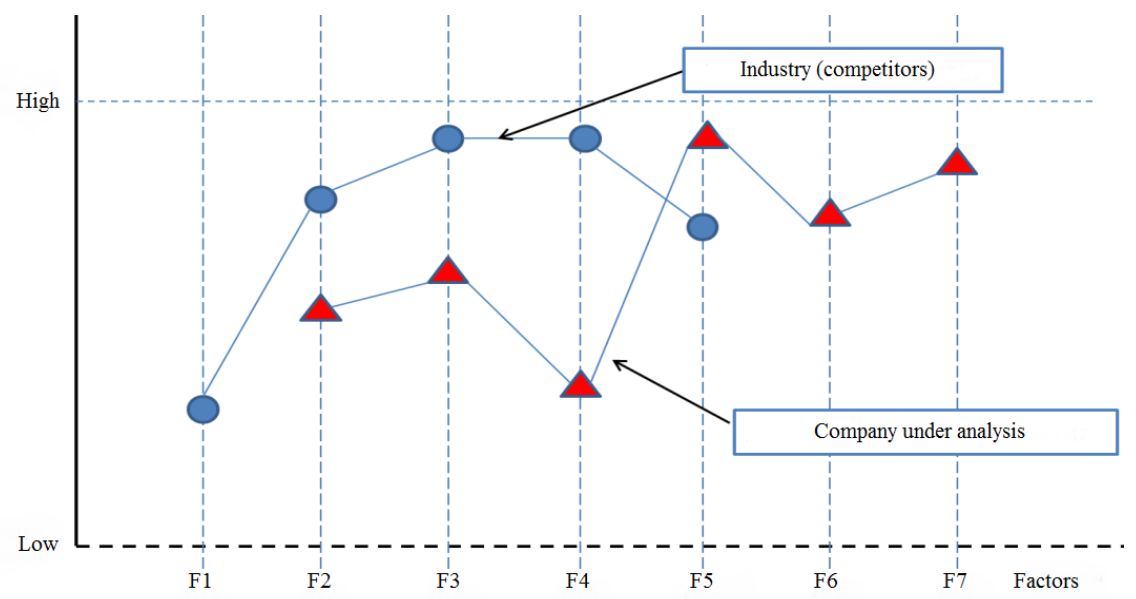

Fig.2. Strategy canvas

The strategy canvas analysis allows a construction company to understand to what 
extent its market strategy is similar to strategies of competing companies. It is easy to determine this similarity using the example of the strategy canvas since graphic forms of the strategy canvas of the construction company under consideration and competing companies having similar approaches are similar [6].

It is offered to consider the four actions framework (Figure 3) after analyzing the strategy canvas (values of various competitive factors for different companies and/or customers).

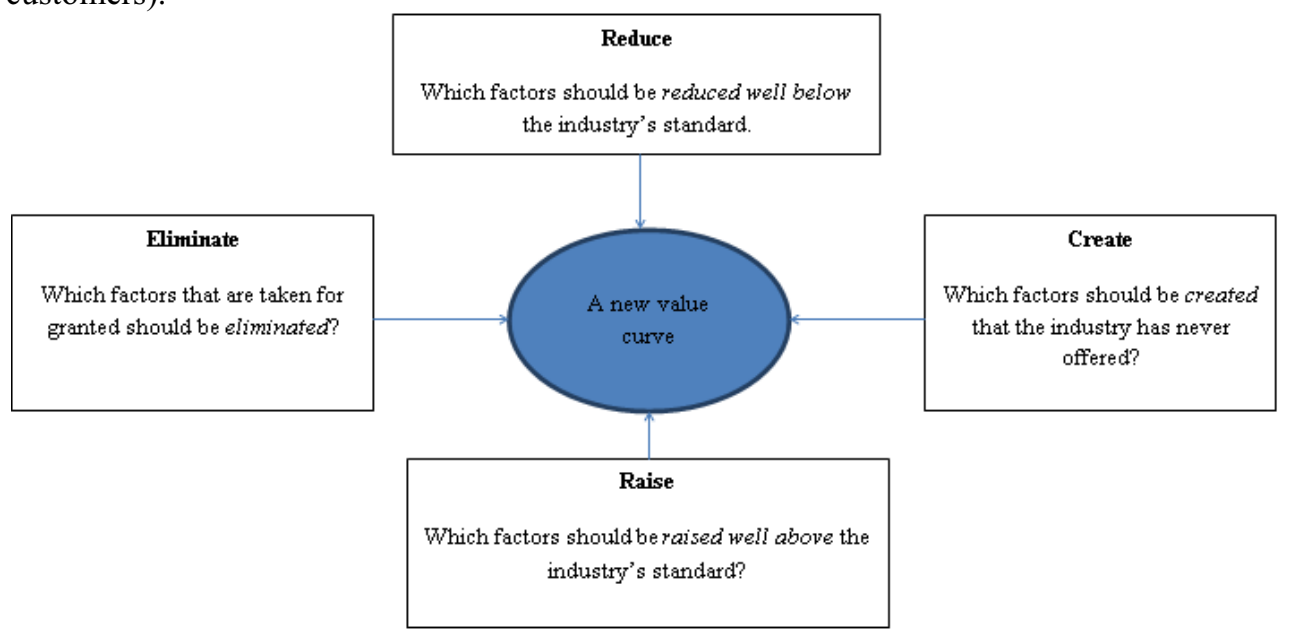

Fig.3. The four actions framework

The chart is designed for further development of the presented four actions framework. It makes companies ask specific questions and take certain measures in all these areas to create a new value curve. When filling this chart with factors and evaluations, the company automatically receives the following advantages over other companies:

- elimination and reduction of factors affecting the competitiveness; it allows to disrupt the "value - costs" balance;

- identification of companies focused only on improvement and creation; it leads to an increase in their costs and makes the products and services too complex;

- easy understanding of the system; it enables managers at all levels to understand and become engaged in the process of its implementation;

- study of every factor with respect to which competition in the industry is initiated and identification of those assumptions that were made unconsciously in the process of competition.

It should be noted that development and effective functioning of facilities included into social infrastructure and their availability to the population is an important condition for the improvement of the quality of human life. Social infrastructure is a set of industries and enterprises providing for normal human life. These are social and cultural facilities, housing and utilities infrastructure, enterprises and organizations relating to the system of health, education, early childhood education, enterprises and organizations dealing with recreation and leisure, retail, catering, sports and health institutions, etc [17-19].

All these greatly affect the attractiveness of real estate as it provides for convenience of living. The infrastructure in the area where real estate is located plays a great role for consumers (real estate buyers). That's why today new buildings and new districts where everything is provided for in advance are in heavy demand. Currently, it is necessary to create acceptable conditions of spatial accessibility of basic social benefits (services) provided by social infrastructure facilities to the population and SMART housing projects can be an example of a synthesis of residential property and social structure elements. 
The new trend of building SMART apartments presupposes increased efficiency of using the space. The approach is based on rational planning of space and allows to place everything necessary for living using the available space to the maximum effect. Unlike typical residential property, SMART buildings are narrower and consist of apartments of a regular shape oriented along the facade of the building, which makes them lighter and visually more spacious. Proper zoning is the main distinguishing feature of SMART standard.

SMART standards:

1. Apartments are built around the needs of residents and created along with recommendations on furniture arrangement revealing apartment functionality.

2. Every meter of space is functional.

3. Layouts promote family atmosphere.

4. Apartments are in buildings with an extended social infrastructure.

5. Minimum restrictions on the private property territory (load-bearing walls are located along the outer perimeter). Transit utility networks with utility meters are partially located at the staircase landing, thus reducing problems associated with the operation of the common infrastructure.

6. Apartments are accompanied by custom space and interior design projects.

7. SMART layouts - pram and bicycle storage rooms, closed yards and no traffic on the territory are provided for by SMART housing projects.

\section{Results}

We can mention SMART housing projects as an example of blue ocean strategy implementation in the area of residential property taking into account social infrastructure factors. We built the strategy canvas for SMART apartments and traditional buildings (see Fig. 4). Consumer preferences in the form of a set of parameters are specified horizontally in this chart. At the same time these parameters are competitive factors of SMART apartments on the market. The scale of proposal value levels is shown vertically.

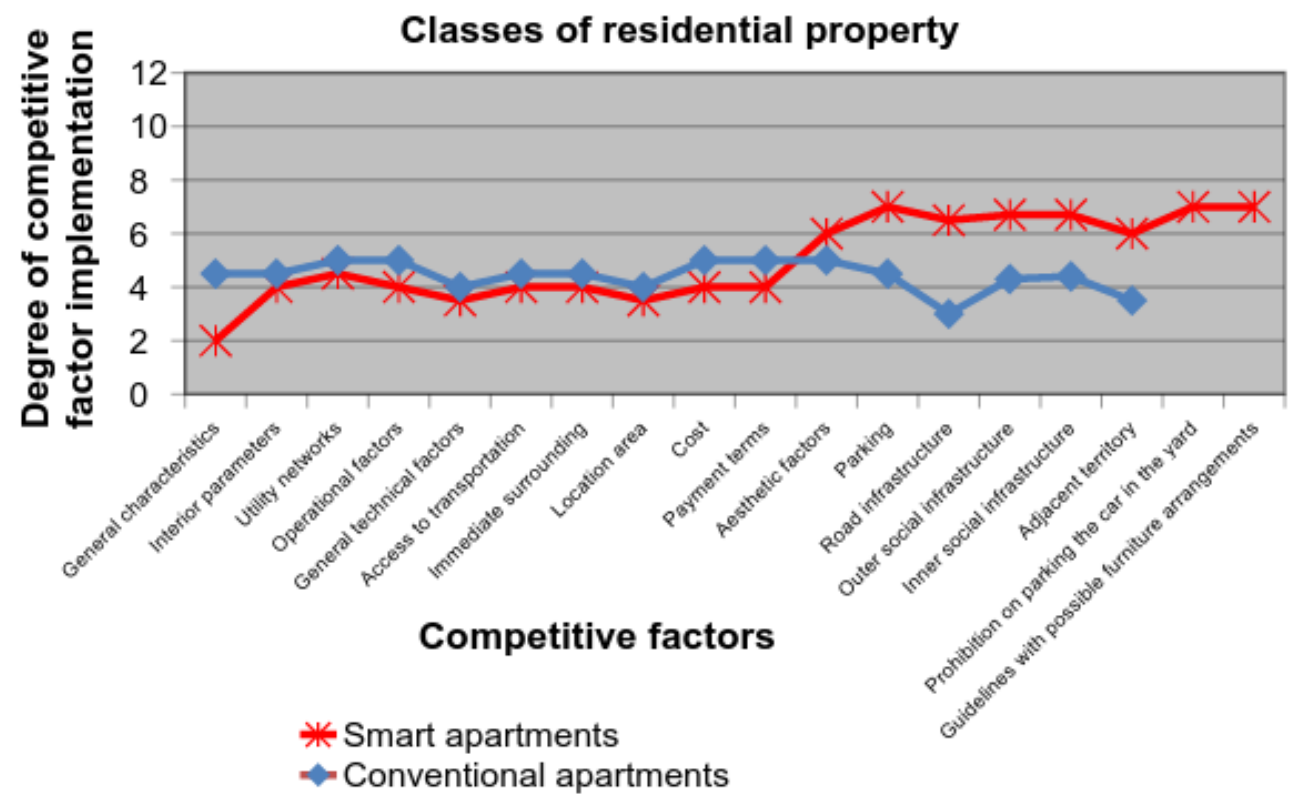

Fig.4. The strategy canvas of conventional and SMART apartments 
Note: The outer social infrastructure includes factors taken into account by the developer when choosing an appropriate site for the construction project (social infrastructure of the district). The developer's impact on the current infrastructure is minimal. The inner social infrastructure includes actions aimed at improving the living comfort, which are included into a specific construction project (social welfare facilities in a residential complex, advanced services provided by the management company, better landscaping of the adjacent territory, etc.).

Then after making the "eliminate-reduce-raise-create" model we will get this picture focused on SMART apartments (see Table 2).

Table 2. The four actions framework for SMART apartments

\begin{tabular}{|l|l|}
\hline \multicolumn{1}{|c|}{ Eliminate } & \multicolumn{1}{|c|}{ Raise } \\
$\begin{array}{l}\text { 1. Structural concept (load-bearing } \\
\text { structures should be used for the } \\
\text { general frame of the building; it will } \\
\text { allow to change the layout to any } \\
\text { choice). }\end{array}$ & $\begin{array}{l}\text { 1. The number of parking lots in the underground } \\
\text { parking garage. } \\
\text { 2. Expand the infrastructure (besides shops and } \\
\text { children's playgrounds create workout facilities, a } \\
\text { stylobate with walk areas, pram and bicycle storage } \\
\text { rooms). } \\
\text { 3. The volume of floor-to-ceiling glazing for some } \\
\text { premises. }\end{array}$ \\
\hline $\begin{array}{c}\text { Reduce } \\
\text { 1. Nonresidential area (efficient use of } \\
\text { space, the functionality of layouts will } \\
\text { be } 40 \% \text { higher as compared to } \\
\text { conventional apartments). }\end{array}$ & $\begin{array}{l}\text { Create } \\
\text { furniture arrangement allowing to save optimum } \\
\text { available space. } \\
\text { 2. Prohibit to park cars in the yard. It will allow to } \\
\text { eliminate excessive noise for residents. }\end{array}$ \\
\hline
\end{tabular}

Then, on the basis of the provided data it is required to analyze this strategy efficiency in the course of implementation of a construction project and decode the value curve (errors in the strategy).

The decision on blue ocean strategy implementation requires to calculate and carry out an analysis of performance indicators in the course of planning and implementation of a construction project. Making the decision can be represented in the form of an algorithm of the developer's actions (see Fig. 5).

After algorithm sequence determination and identification of data of the company's blue ocean strategy it is advisable to proceed to assessment of efficiency of the construction project, if implemented. The efficiency was analyzed following the algorithm stages as exemplified by the construction project (Russia, Moscow region). Financial models for conventional and SMART buildings were developed. Based on the estimates, the following results were obtained (Table 3 ):

Table 3. Results

\begin{tabular}{|l|c|c|}
\hline \multicolumn{1}{|c|}{ Efficiency indicators } & $\begin{array}{c}\text { SMART } \\
\text { apartments }\end{array}$ & $\begin{array}{c}\text { Conventional } \\
\text { apartments }\end{array}$ \\
\hline Revenue from project implementation & 5170301000,00 & 4905068000,00 \\
\hline Expenditures including contingent expenses & 3182770000,00 & 2899012000,00 \\
\hline NPV & 6002400,00 & 5373600,00 \\
\hline IRR & $25.41 \%$ & $21.38 \%$ \\
\hline PI & 1.03 & 1.002 \\
\hline PP, months & 52 & 65 \\
\hline DPP, months & 75 & 88 \\
\hline
\end{tabular}


After analyzing key performance indicators it is possible to conclude that the SMART housing project is more viable and investment-attractive. Therefore, when implementing blue ocean strategy and realizing construction projects following this strategy, the developer will enhance its competitiveness on the real estate market.

Stage 1. Consider strategy implementation methods:

Alternative industries; strategic groups and industries; buyer chain; additional services; functional and emotional attractiveness of the service; progress contingency; engineering system

Stage 2. Analyzing elements of strategy's diagnostic

Strategic canvas: four actions framework "eliminate-reduce-raise-create"

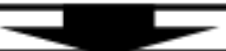

Stage 3. Assessment of risks having an impact on projects and companies: SWOT analysis; risk assessment

Stage 4. Calculate performance indicators

Investment project:

NPV, IRR, PI, PP

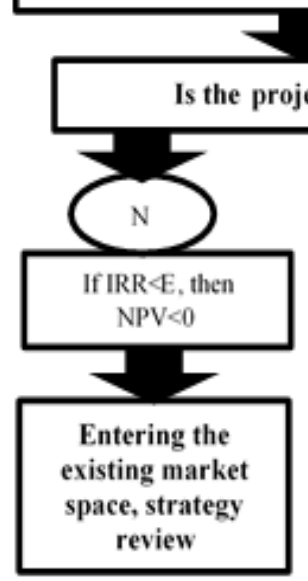

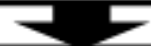

Company's activities:

project delivery time; total market value of real estate items; total cost of project implementation; floor area ratio; Item total area; degree of item occupancy by lessees

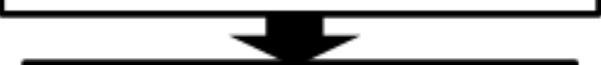

Compliance with the scale of changes in the level of remuneration

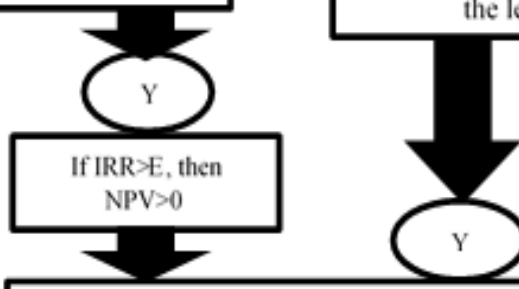

Provision of companies' competitiveness

Blue ocean strategy implementation

Fig.5. Algorithm of the developer's actions

\section{Conclusions}

An unbiased approach to issues concerning the viability and efficiency of application of the strategy described above allows modern construction companies to determine whether free demand is available in the existing market space and "dive into the blue ocean". 
The models described in the paper are an important tool for the analysis of the companies' activities. Their combination allows to consider the company's strategy related to moving away from competition and open up a new market not captured by competitors.

\section{References}

1. M. Porter, Competitive strategy, Techniques for Analyzing Industries and Competitors (The Free Press, 2011)

2. H.Donner, H.-S. Song, M. Wilhelmsson, Journal of Housing Economics 34, 60-68 (2016)

3. A.C. Kasim, M.M.G.M. Abdul Rahman, M. Mohd Raid, 25th International Business Information Management Association Conference - Innovation Vision 2020: From Regional Development Sustainability to Global Economic Growth, IBIMA, 3456-3465 (2015)

4. H. Gorringe, D. Karthikeyan, Journal of South Asia Studies, 1-3 (published online, 2016)

5. Y. Farja, Landscape Research, 1-15 (to be published, 2016)

6. W. Chan Kim, R. Mauborgne, Blue Ocean Strategy (Harvard Business Review Press, expanded edition, 2015)

7. C.H. Wee, Global Business and Organizational Excellence, 36 (2), 34-45 (2017)

8. A. Agnihotri, Journal of Strategic Marketing, 24 (6), 519-528, 2016

9. W.C. Kim, R. Mauborgne, Harvard business review, 92 (5), 60-68 (2014)

10. W.C. Kim, R. Mauborgne, Harvard business review, 1-7 (2015)

11. K. Kahkonen, K., Construction Innovation, 15 (2), 130-133 (2015)

12. W.K. Hughen, D.C. Read, Land Use Policy, 61, 1-11 (2017)

13. R.Peiser, D. Hamilton, Professional real estate development. The ULI guide to the business (Urban Land Institute, 2012)

14. P.H.Brown, How Real Estate Developers Think: Design, Profits, and Community (University of Pennsylvania Press, 2015)

15. A.P.C.Chan, D.W.M. Chan, Y.H. Chiang, B.S.Tang, E.H.W. Chan, K.S.K. Ho, Journal of Construction Engineering and Management, 130 (2), 188-198 (2004)

16. G. Seaden, M. Guolla, J. Doutriaux, J. Nash, Construction Management and Economics 21 (6), 603-612 (2003)

17. H. Osman, H. Structure and Infrastructure Engineering, 12 (1), 108-121 (2016)

18. R. E. Levitt, Journal of Construction Engineering and Management, 133 (9), 619628 (2007)

19. P. Bocchini, D.M. Frangopol, T. Ummenhofer, T. Zinke, Journal of Infrastructure Systems, 20 (2), 04014004 (2014) 